\title{
Speed Control of Pipeline Pig Using the QFT Method
}

\author{
M. Mirshamsi and M. Rafeeyan \\ Department of Mechanical Eng., Faculty of Engineering, Yazd University - Islamic Republic of Iran \\ e-mail: mirshamsi_malihe@yahoo.com - rafeeyan@yazduni.ac.ir
}

\begin{abstract}
Résumé - Contrôle de la vitesse d'un racleur grâce à la méthode de synthèse QFT - Pour qu'une inspection de pipeline soit efficace, l'opération de raclage doit être réalisée à vitesse constante. Cet article présente une méthode simple et efficace fondée sur la théorie QFT (Quantitative Feedback Theory), système de régulation robuste bien connu, permettant de contrôler la vitesse d'un racleur avec bypass dans un oléoduc. Ce régulateur classique commande l'ouverture ou la fermeture d'une soupape installée sur le racleur. Le racleur est ensuite contrôlé grâce au volume de fluide qui le traverse. Pour cela, l'équation dynamique non linéaire du mouvement du racleur est convertie en un ensemble de structures linéaires instables équivalentes via la méthode Sobhani-Rafeeyan (méthode SR). Puis, un régulateur de type QFT est synthétisé. La méthode présentée est conçue pour des pipelines bidimensionnels dans deux situations différentes. Le régulateur créé est simulé numériquement grâce à la boîte à outils Simulink du logiciel MATLAB. Les résultats de la simulation montrent que le régulateur peut être utilisé pour contrôler efficacement la vitesse du racleur lorsque celui-ci passe dans des oléoducs.
\end{abstract}

Abstract - Speed Control of Pipeline Pig Using the QFT Method - To provide an efficient inspection of pipeline, pigging operations must be executed at a constant speed. This paper presents an efficient and simple method based on Quantitative Feedback Theory (QFT), which is a well-known robust controller scheme, for speed control of a pig with bypass flow in a liquid pipeline. This classical-type controller commands the valve installed in the body of the pig to open or close. Then, the pig is controlled using the amount of bypass flow across its body. For this purpose, the nonlinear dynamic equation of motion of the pig is converted to a family of linear uncertain equivalent plants using Sobhani-Rafeeyan's method (SR method). Then, for this family of uncertain equivalent plants, a QFT-type controller is synthesized. The presented method is developed for two-dimensional pipelines in two cases. The designed controllers are simulated numerically using the Simulink toolbox of the MATLAB software. The simulation results show that the designed controller can be used for speed control of the pig with good performance when it runs in the liquid pipelines. 


\section{LIST OF SYMBOLS}

$A_{h} \quad$ Area cross-section of the valve

$D$ Pipeline diameter

$g \quad$ Acceleration of gravity

$l_{\text {pig }} \quad$ Length of the pig

$p_{\text {tail }} \quad$ Pressure in the tail of the pig

$p_{\text {nose }}$ Pressure in the nose of the pig

$V_{\text {pig }} \quad$ Velocity of the pig

$z(x)$ Height of the selected position

$d \quad$ Internal diameter of pipeline

$d_{\text {valve }}$ Bypass valve diameter

\section{Greek symbols}

$\rho \quad$ Density of fluid

$\mu \quad$ Coefficient of friction

\section{INTRODUCTION}

Pigging operations are common and frequently used in the oil and gas transportation industries since it is the only way to monitor the conditions of the inside walls of the buried pipelines for inspection purposes. There are several types of pigs and each type is designed for a desired purpose. All of the pigs act better if they run at a near constant speed. Most pigging operations such as batching, cleaning and liquid removal in gas pipelines are done at normal operating velocities with the regular flow of the product. This velocity is generally in the range of $1-5 \mathrm{~m} / \mathrm{s}$ in liquid pipelines and $2-7 \mathrm{~m} / \mathrm{s}$ in gas pipelines [1]. The smart pigs (pipeline inspection gauges) are usually equipped with a number of transducers which are installed on it circumferentially for detection of surface defects such as cracks, corrosion, etc. Frequency response limitations of these transducers, which are often MFL (Magnetic Flux Leakage) type, lead to keeping their speeds nearly constant during data acquisition. The more accurate the data acquisition, the greater the decrease in cost and time of the maintenance and future dangerous accidents. To keep the velocity of the pig constant, a bypass flow pig type can be used. The speed of this pig is controlled using the amount of bypass flow across its body. The amount of bypass flow is regulated by a valve installed on it. This pig is driven by injected fluid flow behind its tail and expelled fluid flow in front of its nose.

Few studies have been done on the motion of pigs, especially concerning their speed control in pipelines. Some of these studies are experimental research or have a commercial basis. Dynamic modeling of various pigs is one of the current subjects that several interesting investigations have been conducted on. It seems that the first one was introduced by [2]. This modeling was modified and improved by removing some limitations in [3]. The first pigging model based on full twophase transient flow formulation was proposed by [4]. This model is composed of correlations for pressure drop across the pig, slug holdup, pigging efficiency, a pig velocity model and a gas and liquid mass flow boundary condition applied to the slug front. Some other complementary research was also reported for pigging simulation in two-phase flow straight pipelines [5-8]. Transient pig motion through gas and liquid pipelines was presented by [9]. Modeling and simulation for pig flow control in a natural gas pipeline was studied by [10]. This paper solved the governing partial differential equations of the pig using the method of characteristics. Another modeling with a similar solution method but with more accurate equations was studied by [11]. It seems that the first investigation which deals with the speed control of a bypass flow pig in a natural gas pipeline was [1]. In this research, a simple nonlinear controller was proposed for controlling the pig velocity when it moves in a natural gas straight pipeline. Also, to provide an efficient tool to assist in the control and design of pig operations through pipelines, a numerical code has been developed by [12]. The results obtained with the code in this research were compared with experimental results and a good agreement between the two was obtained. In all these studies mentioned, researchers assumed that the pig moves in a straight line in the plane. Simulation of a small pig in space pipeline was studied first by [13]. In this research, the effect of the flow field on the pig's trajectory was ignored. This effect was considered in [14] for a bypass flow pig in space pipeline.

The objective of the present work is to synthesize a linear classical feedback controller for speed control of the bypass flow pig to keep its velocity near a constant value. To do this, the nonlinear equation of motion of the pig is converted to a family of linear uncertain equivalent plants using the SR method [15]. Then, for two different case studies, QFT-type robust controllers are synthesized for the family of linear uncertain plants. The designed controllers are simulated on the main system (nonlinear system). The simulation results show that these controllers can control the speed of the pig perfectly.

\section{GOVERNING EQUATION OF THE PIG MOTION}

Figure 1 shows a typical small pig moving inside a twodimensional pipeline and its free body diagram. The weight of the pig, $m g$, dry friction, $F_{\mu}=\mu N$, normal force by the pipe wall, $N$, upstream acting force of the fluid, $F_{1}$ and downstream acting force of the fluid, $F_{2}$, are the forces acting on the pig. The dynamic equations of the pig, derived from Newton's second law along the tangential and normal directions, are as follows:

$$
\begin{gathered}
N-m g \cos \theta=m a_{n} \\
F_{1}-F_{2}-m g \sin \theta-\operatorname{sgn}(\dot{x}) F_{\mu}=m a_{t}
\end{gathered}
$$

where $\theta$ is the angle of the tangent to the centerline curve of the pipeline with respect to the $x$-axis at any point; i.e. if $f(x)$ 


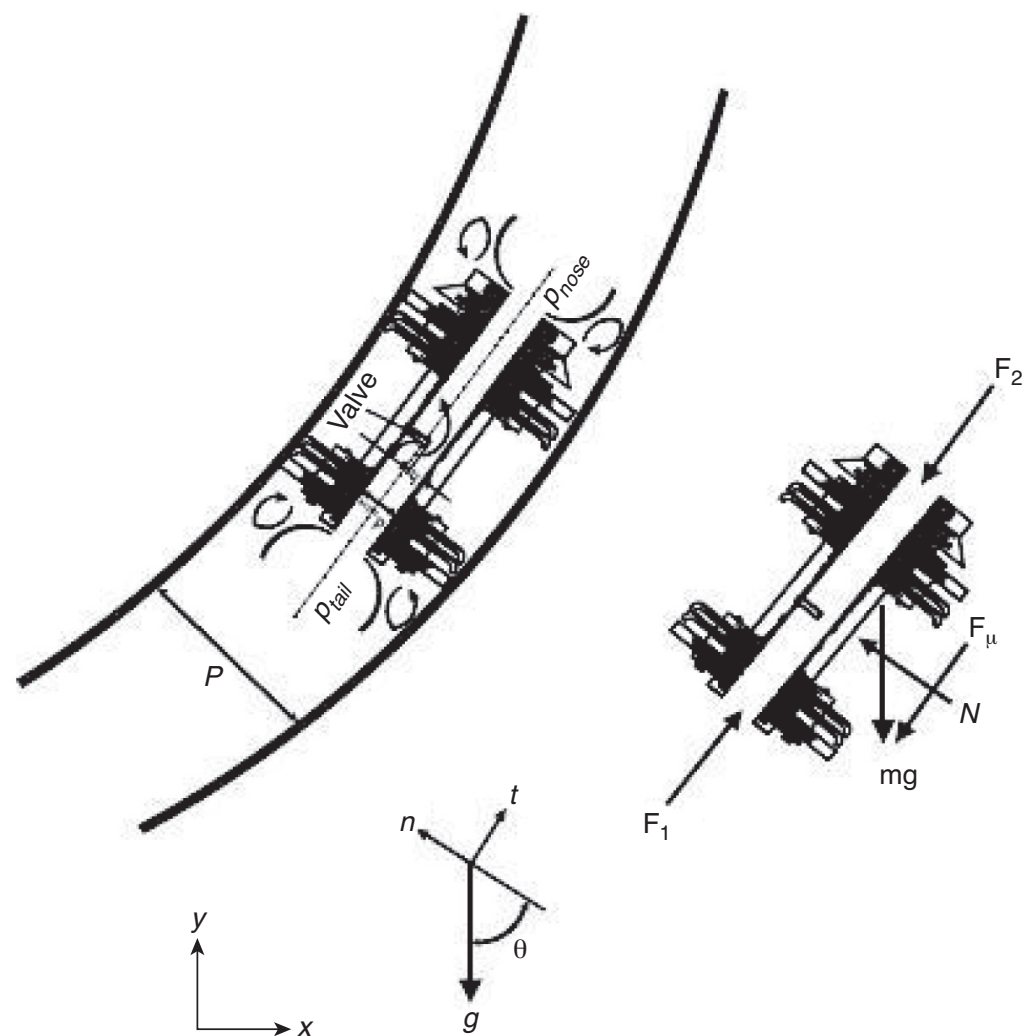

Figure 1

Schematic view of a pig inside a planer pipeline.

is assumed to be the function of the centerline of the pig, thus we can write:

$$
\theta=\tan ^{-1} f^{\prime}(x), \cos \theta=\frac{1}{\sqrt{1+f^{\prime}(x)^{2}}}
$$

If $s$ measures along the pig's path and the radius of curvature of the path is $R$, then we can derive both accelerations of the pig as follows:

$$
\begin{gathered}
V_{p i g}=\dot{s}=\sqrt{1+f^{\prime}(x)^{2}} \dot{x} \\
a_{n}=\frac{V_{p i g}^{2}}{R}=\frac{f^{\prime \prime}(x)}{\sqrt{1+f^{\prime}(x)^{2}}} \dot{x}^{2} \\
a_{t}=\frac{d^{2} s}{d t^{2}}=\frac{f^{\prime \prime}(x) f^{\prime}(x)}{\sqrt{1+f^{\prime}(x)^{2}}} \dot{x}^{2}+\ddot{x}^{2} \sqrt{1+f^{\prime}(x)^{2}}
\end{gathered}
$$

The term $F_{1}-F_{2}$ on the left side of Equation (2) can be derived as follows [13]: see Equation (7).
In general, the pressure difference between the tail and the nose of the bypass hole in the pig $\left(p_{\text {tail }}-p_{\text {nose }}\right)$ is established from three parts; i.e. pressure losses from a sudden contraction at the tail $\left(K_{S C}\right)$, the valve inside the hole $\left(K_{V}\right)$ and a sudden expansion at the nose $\left(K_{S E}\right)$. The following relations are suggested for the pressure difference and the loss coefficients in the fluid mechanics books and papers, e.g. [1]:

$$
p_{\text {tail }}-p_{\text {nose }}=\frac{K_{\text {total }} \rho\left(V_{h}-V_{\text {pig }}\right)^{2}}{2}
$$

where:

$$
\begin{gathered}
K_{\text {total }}=K_{S C}+K_{V}+K_{S E} \\
K_{S C}=0.42\left(1-\frac{d_{\text {valve }}^{2}}{d^{2}}\right) \\
K_{V}=f\left(\frac{h}{d_{\text {valve }}}\right), K_{S E}=1-\frac{d_{\text {valve }}^{2}}{D^{2}}
\end{gathered}
$$

$$
F_{1}-F_{2}=\left(p_{\text {tail }}-p_{\text {nose }}\right) A_{h}-\left[f \rho \frac{l\left(x+5 l_{\text {pig }}\right)-l(x)}{D} \frac{V^{2}}{2}+g \rho Z\left(x+5 l_{\text {pig }} \cos \theta\right)-\rho g Z(x)\right] A-4 \rho g A l_{\text {pig }} \frac{f^{\prime}(x)}{\sqrt{1+f^{\prime}(x)^{2}}}
$$




$$
\min \left(K_{\text {total }}\right)=\left(1-\frac{d_{\text {valve }}^{2}}{D^{2}}\right)\left(1.42-\frac{d_{\text {valve }}^{2}}{D^{2}}\right)
$$

Substitutions (3) and (5) in (1) give the normal force $N$ as follows:

$$
N=m\left[\frac{f^{\prime \prime}(x)}{\sqrt{1+f^{\prime}(x)^{2}}} \dot{x}^{2}+\frac{1}{\sqrt{1+f^{\prime}(x)^{2}}} g\right]
$$

The final equation of the pig can be derived by substituting all the terms in (2) as follows: see Equation (11).

\section{QFT CONTROLLER DESIGN}

\section{General Formulation}

Numerical simulation of Equation (11) shows that the pig speed varies with respect to time. In order to control the pig speed, the pig's nonlinear system is converted to a family of linear uncertain equivalent systems using the SR method. In order to demonstrate the remarkable performance of the proposed control approach, two different case studies are considered and QFT controllers are designed.

Using the open-loop transmission, each controller should be synthesized such that the closed-loop system is stable and also satisfies the following conditions.

\section{Robust Stability}

The stability margin can be specified in terms of a phase margin, a gain margin or the corresponding $M_{L}$ contour on the Nichols Chart (NC) using the associated magnitude in decibels $(\mathrm{dB})$ [16]. If any one of the three stability requirements is specified, the remaining two can be calculated. The $M_{L}$ contour is the stability specification used directly for the QFT design technique, placing an upper limit on the magnitude of the closed-loop frequency response:

$$
\left|\frac{1}{1+L(j \omega)}\right| \leq M_{L} \text { for all } P, \omega \geq 0
$$

The $M_{L}$ contour on the NC therefore forms a boundary which must not be violated by a plot of the open-loop transmission $L(s)=G(s) P(s)$. Throughout the design, $M_{L}$ is chosen to be $1.58 \mathrm{~dB}$.

\section{Robust Performance}

The following design constraint is used to ensure adequate tracking performance:

$$
\left|T_{L}(j \omega)\right| \leq\left|\frac{L(j \omega)}{1+L(j \omega)}\right| \leq\left|T_{U}(j \omega)\right| \text { for all } P, \omega \geq 0
$$

Equation (13) implies that the system's response to the step input should be placed in a predefined region specified by upper and lower bounds, denoted as $T_{U}(j \omega)$ and $T_{L}(j \omega)$, respectively. Suppose that:

- the system's response to the step input is required to settle in $t_{s} \leq 2.5 \mathrm{~s}$;

- an overshoot of $M_{L}=1.4$ is appropriate.

The following transfer functions can be selected so as to define the desired tracking bounds with the aforementioned specifications:

$$
\begin{gathered}
T_{U}(j \omega)=\frac{4.938(s+4)}{s+2 \pm j 3.969} \\
T_{L}(j \omega)=\frac{8400}{(s+3)(s+4)(s+10)(s+70)}
\end{gathered}
$$

These two specifications generate robust bounds on $L_{0}(j \omega)$ which is a nominal loop transmission at selected frequencies, and the bounds are plotted on the NC. The synthesized $L_{0}(j \omega)$ must lie on or just above the bound at each frequency to satisfy the required performance. The proposed compensator $G$ is designed by adding appropriate poles and zeros to the nominal loop function so that it lies inside the acceptable regions.

The designed compensator, however, guarantees only that the variation in $|L(j \omega) /(1+L(j \omega))|$ is less than or equal to that allowed. Therefore, it is necessary that a prefilter be designed to ensure robust performance in the tracking problem.

\section{Application to the Proposed System}

The dynamic equation of motion of the pig can be written as:

$$
\begin{aligned}
& \ddot{x}=W(t) \frac{\left(V-\dot{x} \sqrt{1+c^{2}}\right)^{2}}{\sqrt{1+c^{2}}}-f \rho \frac{5 l_{\text {pig }}}{D m \sqrt{1+c^{2}}} \frac{V^{2}}{2} \\
& +4 \rho g A l_{p i g} \frac{c}{m\left(1+c^{2}\right)}-g \frac{c^{2}}{1+c^{2}} \\
& -b \mu\left(\frac{d}{1+c^{2}} \dot{x}^{2}+\frac{g}{1+c^{2}}\right)-\frac{c d}{1+c^{2}} \dot{x}^{2}
\end{aligned}
$$

where:

$$
W(t)=\frac{K_{\text {total }} \rho A^{2}}{2 m A_{h}}
$$

$$
\begin{gathered}
\frac{K_{\text {total }} \rho A^{2}\left(V-\dot{x} \sqrt{1+f^{\prime}(x)^{2}}\right)^{2}}{2 A_{h}}-f \rho \frac{5 l_{p i g}}{D} \frac{V^{2}}{2}+4 \rho g A l_{p i g} \frac{f^{\prime}(x)}{\sqrt{1+f^{\prime}(x)^{2}}}-m g \frac{f^{\prime}(x)}{\sqrt{1+f^{\prime}(x)^{2}}} \\
-\operatorname{sgn}(\dot{x}) m \mu\left[\frac{f^{\prime \prime}(x)}{\sqrt{1+f^{\prime}(x)^{2}}} \dot{x}^{2}+\frac{g}{\sqrt{1+f^{\prime}(x)^{2}}}\right]=m\left[\frac{f^{\prime}(x) f^{\prime \prime}(x)}{\sqrt{1+f^{\prime}(x)^{2}}} \dot{x}^{2}+\ddot{x} \sqrt{1+f^{\prime}(x)^{2}}\right]
\end{gathered}
$$




$$
\begin{gathered}
b=\operatorname{sgn}(\dot{x}) \\
c=f^{\prime}(x), d=f^{\prime \prime}(x)
\end{gathered}
$$

Since $A_{h}$ is time-variant, $W(t)$ can be considered as control input. $b, c$ and $d$ can be considered as system uncertainties. Now, the nonlinear system governed by Equation (15) is replaced with a family of linear time equivalent systems using the SR method. This method uses an arbitrary family of output functions for construction of this equivalent family, substitutes these functions in dynamic equations, obtains the Laplace transform of the equation and obtains a family of linear equivalent uncertain transfer functions for a nonlinear system [14]. In this study, a set of step functions with uncertain height is considered arbitrarily, as follows:

$$
V_{p i g}=\dot{x}=a . u(t)
$$

where $u(t)$ is a step function. Substituting this function in the dynamic equation of the pig (15) and getting the Laplace transform of the equation, the transfer function of linear equivalent plants is obtained as follows:

$$
P=\frac{V_{p i g}(s)}{W(s)}=\frac{a V^{2}-2 a^{2} V \sqrt{1+c^{2}}+\left(1+c^{2}\right) a^{3}}{a \sqrt{1+c^{2}} s+\left(-k+\frac{b \mu d+c d}{1+c^{2}} a^{2}\right) \sqrt{1+c^{2}}}
$$

where:

$$
\begin{aligned}
& k=-f \rho \frac{5 l_{p i g}}{m D \sqrt{1+c^{2}}} \frac{V^{2}}{2}+4 \rho g A l_{p i g} \frac{c}{m\left(1+c^{2}\right)} \\
& -g \frac{c}{1+c^{2}}-b \mu \frac{g}{1+c^{2}}
\end{aligned}
$$

Now two different case studies are considered and QFT controllers and prefilters are designed for each one.

\section{NUMERICAL EXAMPLES}

Case 1

For the first case study, let us assume a 2D pipeline with the linear equation as $y(x)=x$. The numerical values for the mass of the pig, length of the pig, pipe diameter and bypass diameter are assumed to be $50 \mathrm{~kg}, 0.3 \mathrm{~m}, 0.25 \mathrm{~m}$ and $0.12 \mathrm{~m}$,

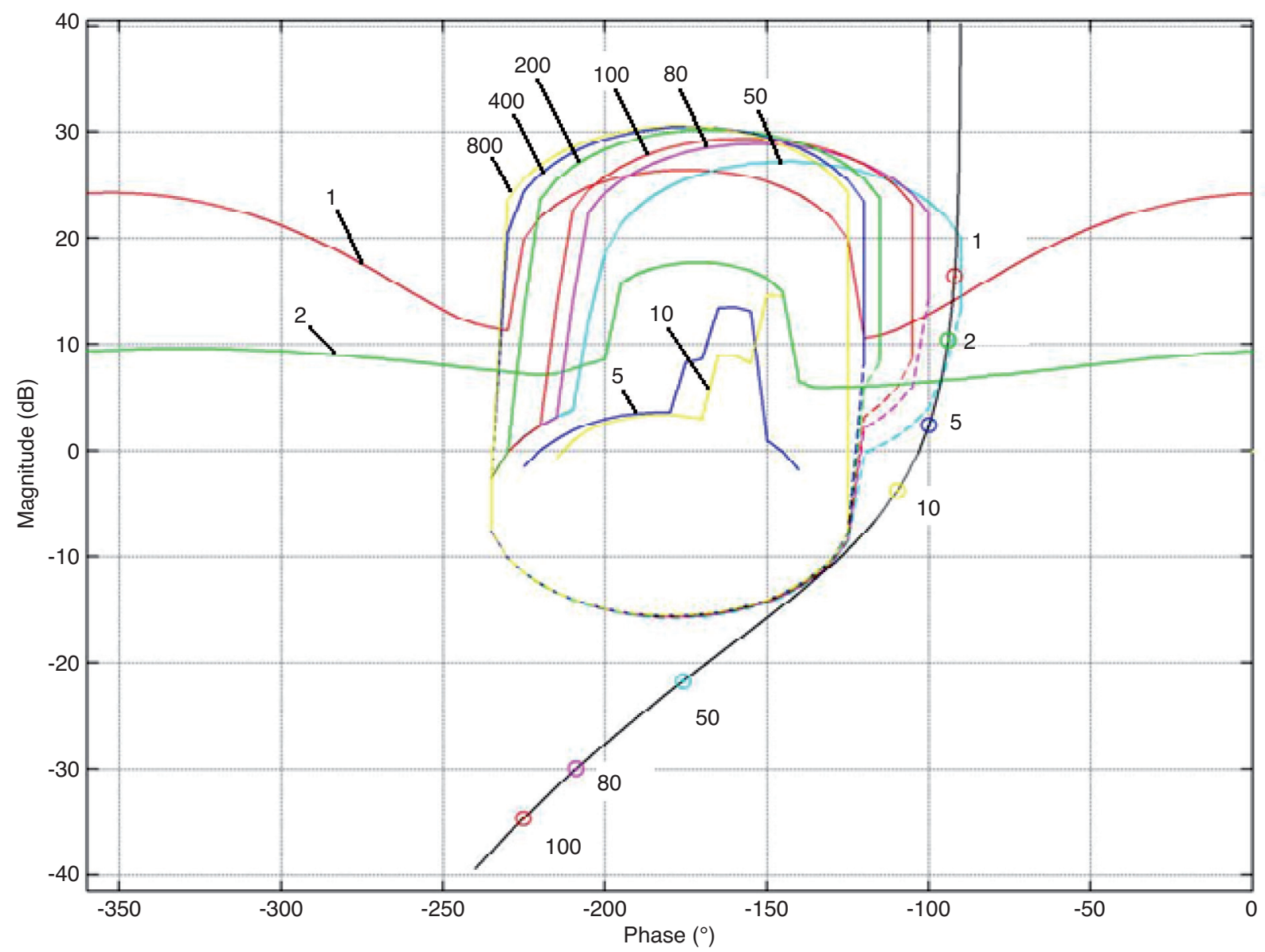

Figure 2

Nominal loop-shaping for case 1. 
respectively. The fluid is water with density of $1000 \mathrm{~kg} / \mathrm{m}^{3}$ and velocity of $6 \mathrm{~m} / \mathrm{s}$. The dynamic and static coefficients of friction are assumed to be 0.2 and 0.3 , respectively. The pig position at initial time is $x(0)=y(0)=0$. Since $f^{\prime \prime}(x)=0$ and $f^{\prime}(x)=1$ in this example, $c=1$ and $d=0$. It is assumed that $b \in[-11], a \in[15]$. QFT compensators and prefilters are designed for the family of uncertain linear time-invariant equivalent plants (20) using the numerical values above. The prefilter $H_{1}$ and compensator $G_{1}$ are designed as:

$$
\begin{gathered}
H_{1}(s)=\frac{1}{s / 29.19+1} \\
G_{1}(s)=\frac{25.24}{s\left(s^{2} / 137.1+2.33 s / 137.1+1\right)}
\end{gathered}
$$

In Figure 2 colored lines show the resulting QFT design bounds (stability bounds and performance bounds) for the pre-determined set of design frequencies $\omega=\{1,2,5,10,50$, $80,100,200,400,800\}$ and the black line shows the loop shaping $L(j \omega)$ for these frequencies. It is noted that the plot at

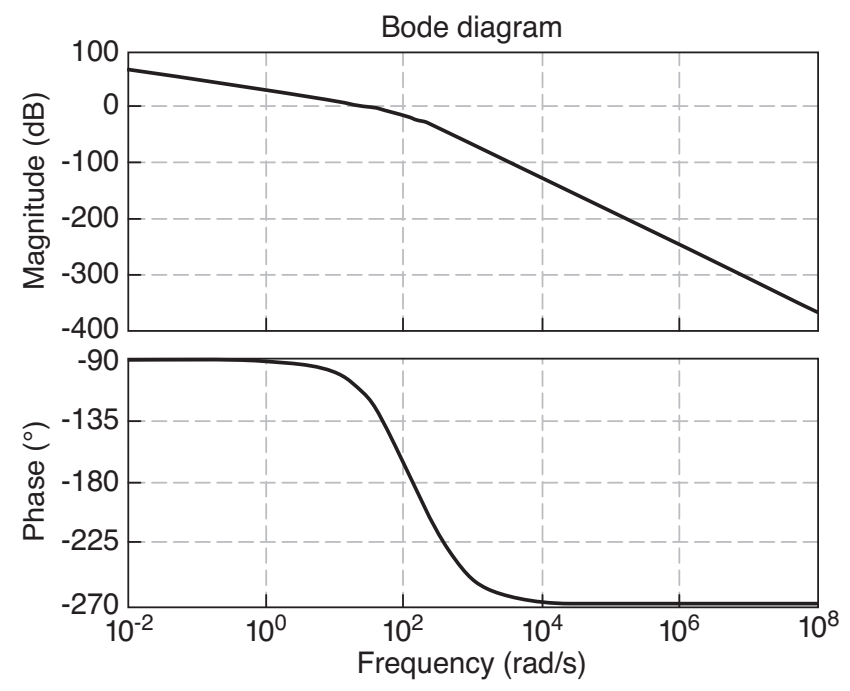

Figure 3

The Bode plot of $G_{1}(s)$ for case 1 .

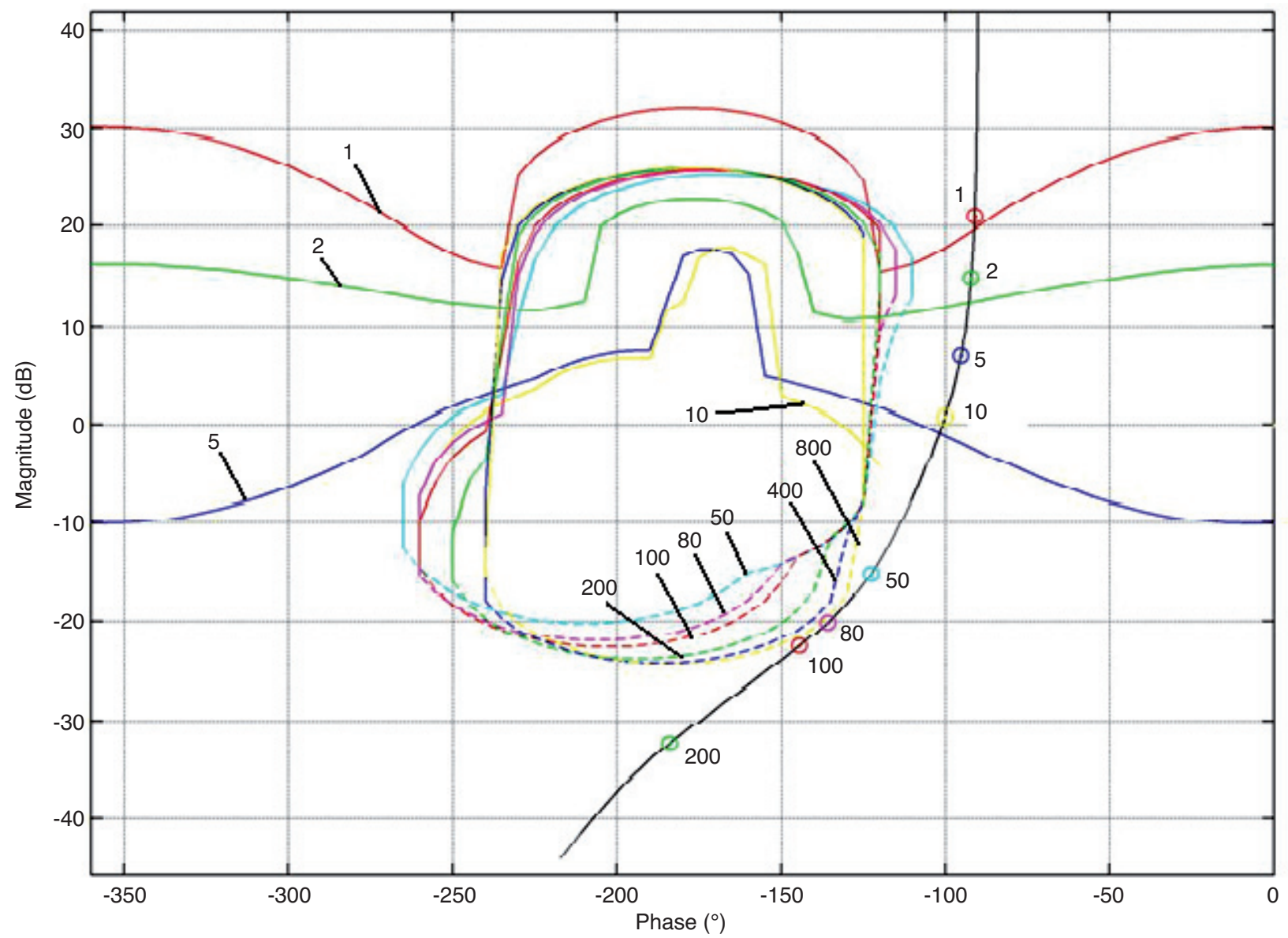

Figure 4

Nominal loop-shaping for case 2 . 

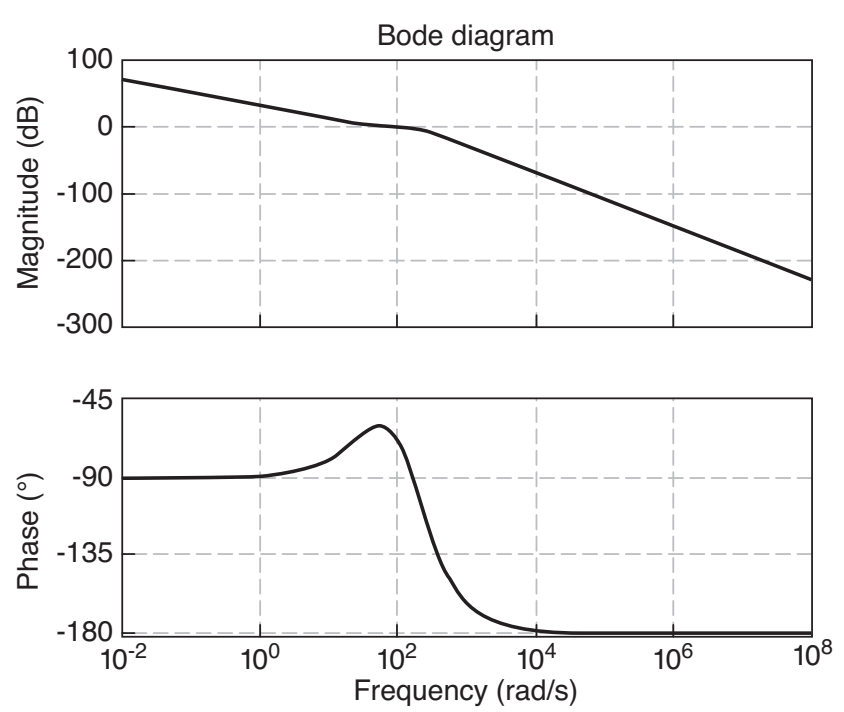

Figure 5

The Bode plot of $G_{2}(s)$ for case 2 .

each chosen frequency satisfies the specified bound, that is, $L(j \omega)$ does not violate the U-contour (for stability) and any points of $L(j \omega)$ are on or above the performance bound curve for the frequencies. Figure 3 demonstrates the Bode plot of the first designed controller, $G_{1}(s)$.

Case 2

For the second case, a pipeline with the curve equation as $y(x)=-0.5(x+\sin x)$ is selected. The numerical values for the mass of the pig, length of the pig, pipe diameter, bypass diameter, fluid density and velocity are the same as case 1 . The pig position at initial time is at $x(0)=y(0)=0$. Since $-0.5 \leq f^{\prime \prime}(x) \leq 0.5$ and $-1 \leq f^{\prime}(x) \leq 0$ in this example,

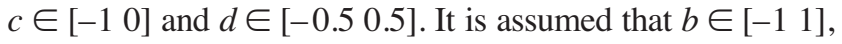
$a \in$ [1 5]. The prefilter $H_{2}$ and compensator $G_{2}$ are designed for this case using the QFT approach.

$$
\begin{gathered}
H_{2}(s)=\frac{1}{s / 11+1} \\
G_{2}(s)=\frac{32.43(s / 35.28+1)}{s\left(s^{2} / 196+1.712 s / 196+1\right)}
\end{gathered}
$$

The designed compensator $G_{2}$ and its Bode plot for case 2 are depicted in Figures 4 and 5.

\section{RESULTS AND DISCUSSION}

Figures 6 and 7 show the velocity of the pig for cases 1 and 2 , respectively. These figures also show that the velocity of the pig follows the desired velocity (i.e. $3 \mathrm{~m} / \mathrm{s}$ ) very soon. It is worth noting that the designed controllers were simulated

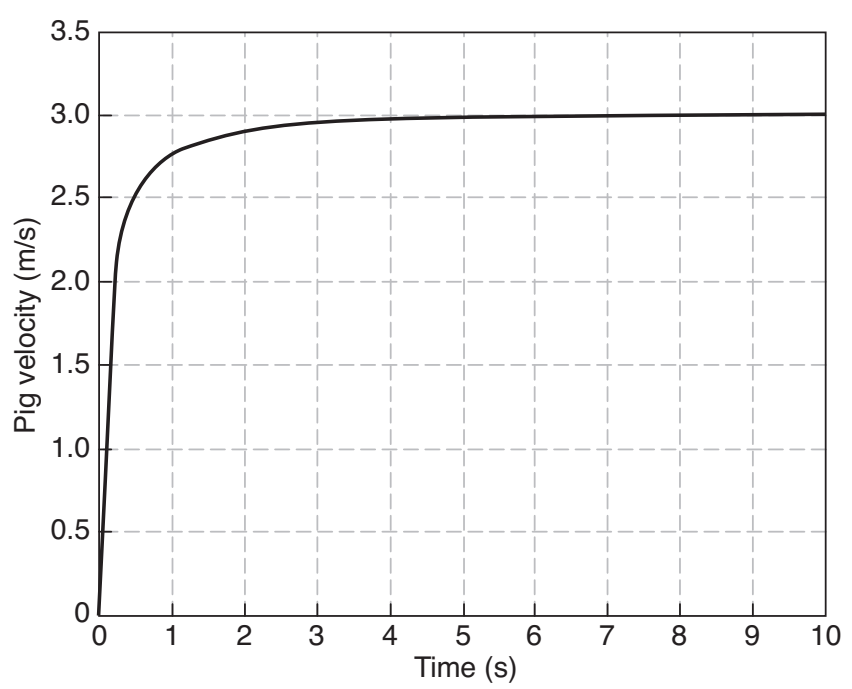

Figure 6

Simulated pig velocity for case 1 .

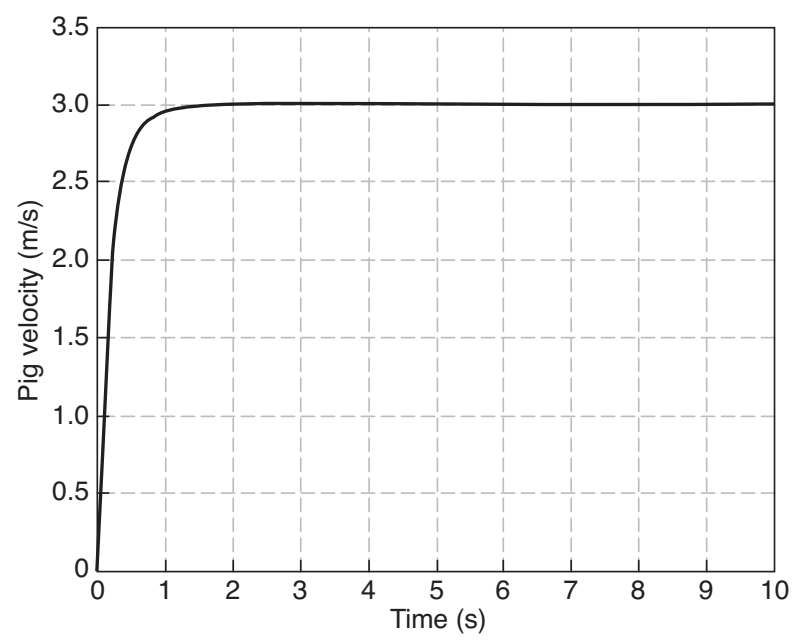

Figure 7

Simulated pig velocity for case 2 .

on the main nonlinear plant, not on a linear equivalent plant, as obtained in (20). Therefore, we can conclude that the present QFT-based controller design can be used for such pig speed control problems. Figures 3 and 5 show that the designed controllers are realizable because their bandwidths are limited.

Figures 8 and 9 show the changes of valve diameter for cases 1 and 2, respectively. As these figures represent, the valve must be closed approximately at the initial time and rapidly opened some seconds later. This is because of the large slope of the pipeline curve at these times. After some seconds, the pig gets a constant velocity and therefore the required diameter of the valve becomes constant. Simulation diagrams for both cases are shown in Figures 10 and 11. 


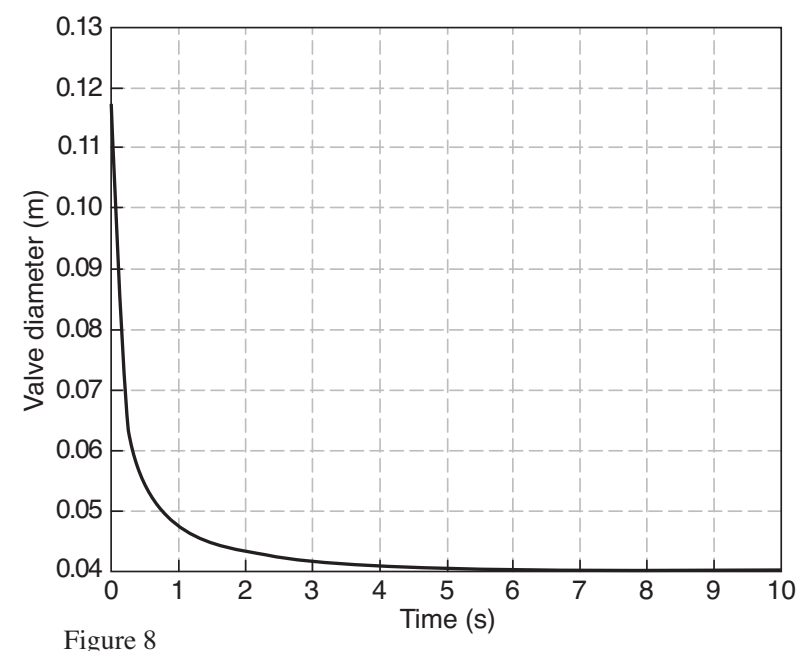

Figure 8

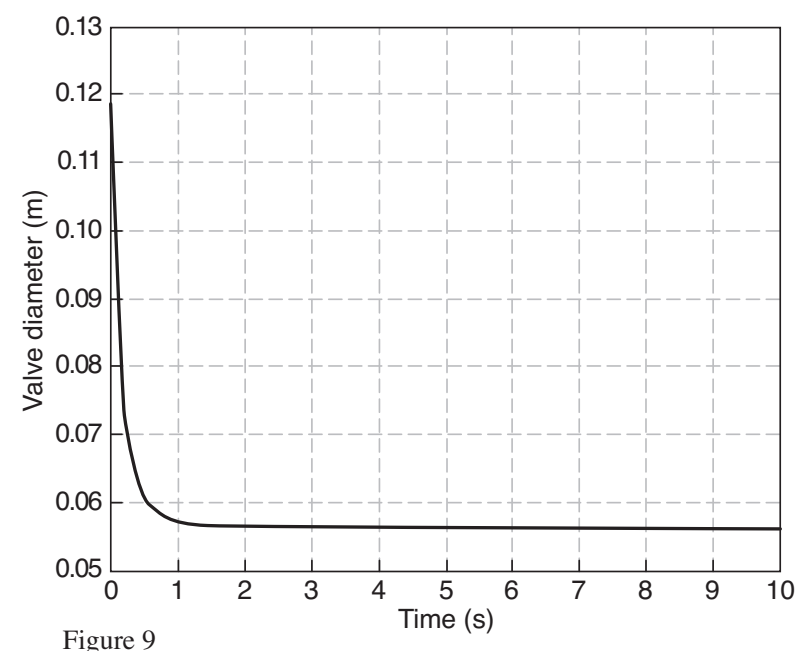

Changes in valve diameter, for case 2 .

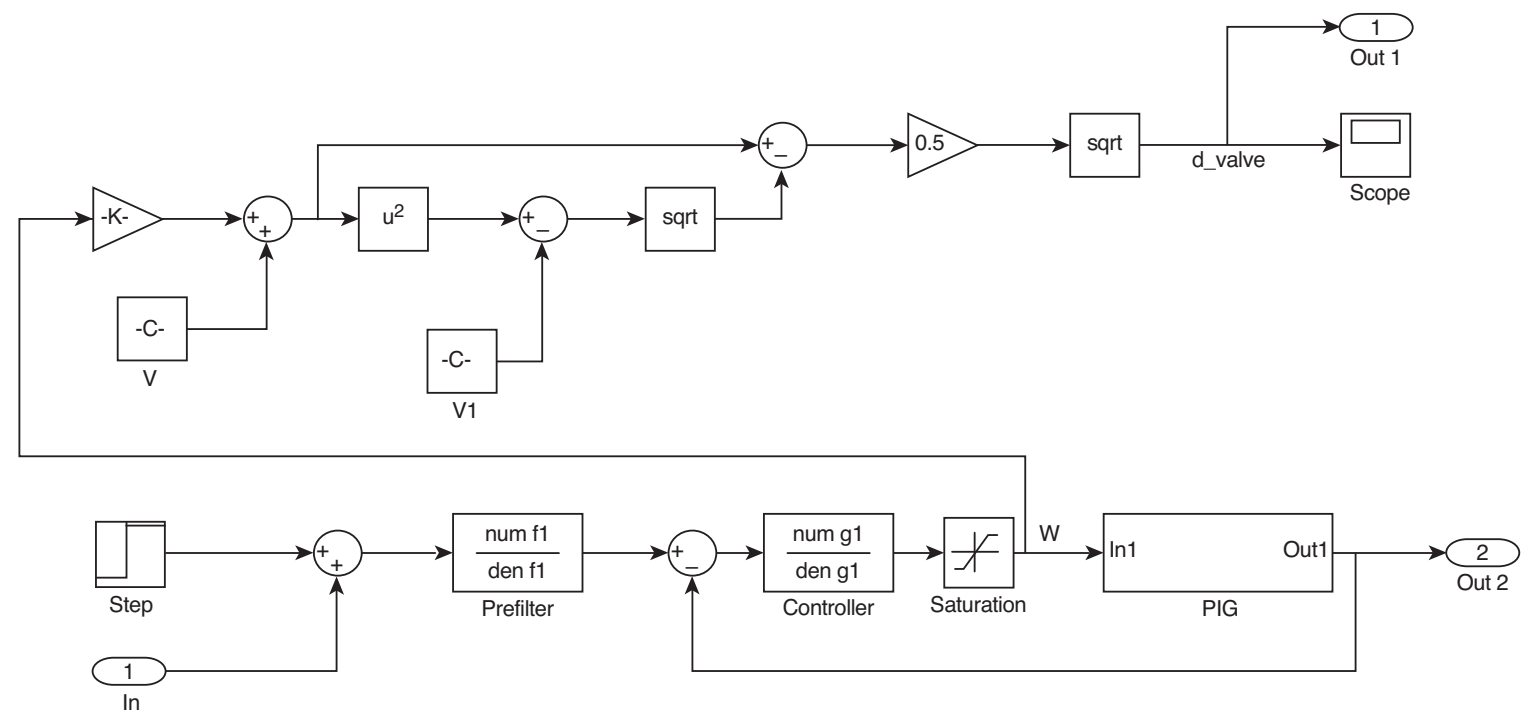

Figure 10

Block diagram.

\section{CONCLUSIONS}

This paper proposed a new and simple controller design method to maintain the speed of a pipeline pig. This method, which is called Sobhani-Rafeeyan's method, replaces the nonlinear dynamic equation of the pig with bypass flow in liquid pipeline with a family of uncertain linear systems. Then, a robust controller using the Quantitative Feedback Theory (QFT) method was synthesized for this family of uncertain linear systems. The designed controller was simulated on the original nonlinear system and good results were obtained. The results from the two studies showed that the speed of the pig reaches its desired value very soon. This research is the first application of the QFT method, which is a well-known robust control method, in the area of speed control of the pig. Also, it is the first control method for pigs whose paths are two-dimensional. It is expected that this method can be developed for speed control of a pig in a natural gas pipeline. Also, this method can include some uncertainty of parameters such as: density of fluid, coefficient of friction, length of the pig and so on. The final designed controller is always of classical type and realizable. 


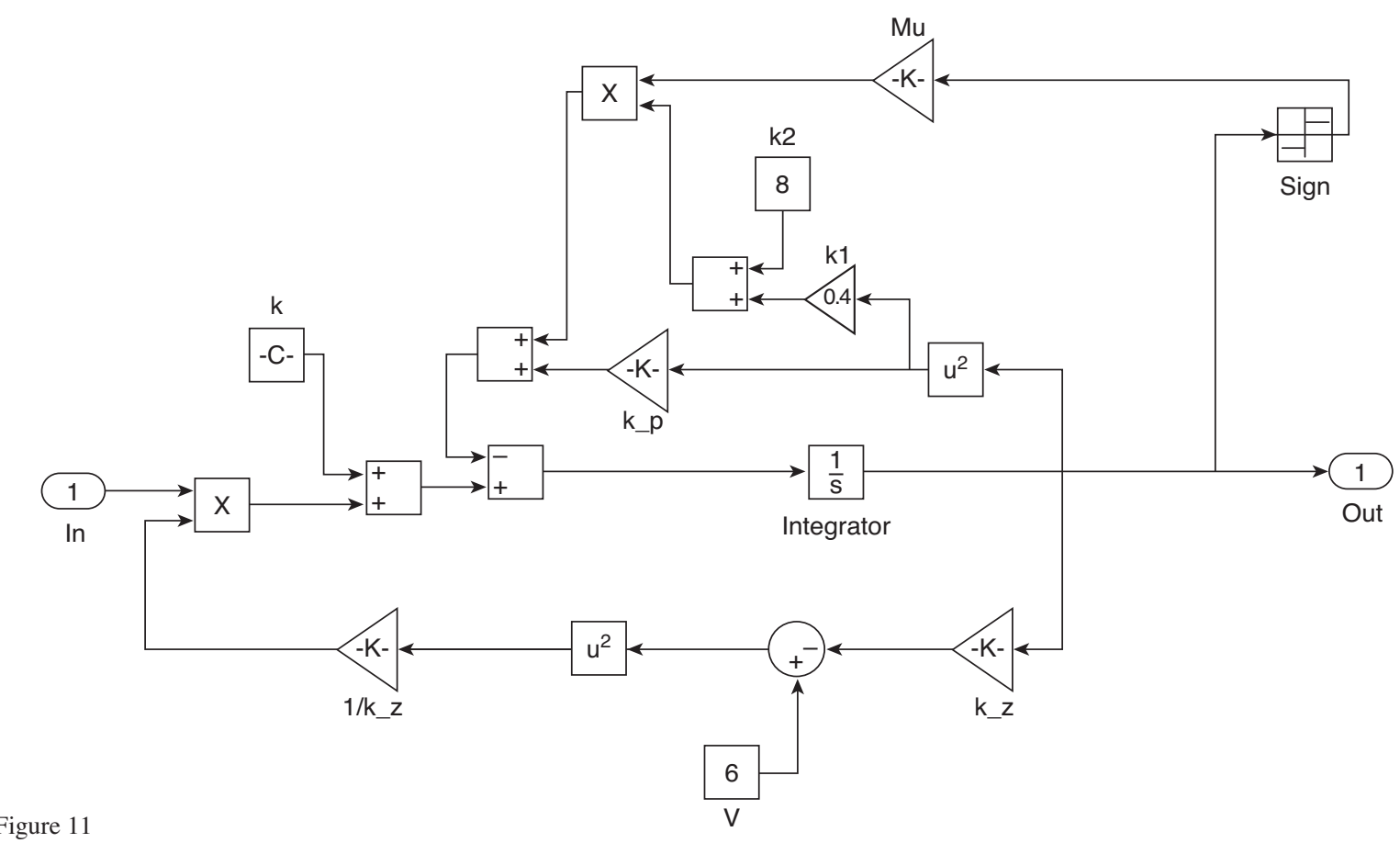

Dynamic of pig.

\section{REFERENCES}

1 Nguyen T.T., Yoo H.R., Rho Y.W., Kim S.B. (2001) Speed control of pig bypass flow in natural gas pipeline, International Symposium on Industrial Electronics, Pusan, Korea, June 12-16.

2 McDonald A., Baker O. (1964) Multiphase flow in (Gas) pipelines, Oil Gas J. 62, 24, 68-71; Oil Gas J. 62, 25, 171-175; Oil Gas J. 62, 26, 64-67.

3 Barua S. (1982) An experimental verification and modification of the McDonald and Baker pigging model for horizontal flow, PhD Thesis, University of Tulsa, Texas.

4 Kohda K., Suzukawa Y., Furukwa H. (1988) A new method for analyzing transient flow after pigging scores well, Oil Gas J.9, 40-47.

5 Minami K., Shoham O. (1991) Pigging dynamics in two-phase flow pipelines: experiment and modeling, SPE Prod. Facil. 10, 4, 225-231.

6 Taitel Y., Shoham O., Brill J.P. (1989) Simplified transient solution and simulation of two-phase flow in pipelines, Chem. Eng. Sci. 44, 1353-1359.

7 Scoggins Jr. (1977) Numerical simulation model for transient two-phase flow in a pipeline, $P h D$ Thesis, University of Tulsa, Texas.

8 Xiao-Xuan X., Gong J. (2005) Pigging simulation for horizontal gas-condensate pipelines with low-liquid loading, Journal of Petroleum Science Engineering 48, 272-280.
9 Nieckele A.O., Braga A.M.B., Azevedo L.F.A. (2001) Transient pig motion trough gas and liquid pipelines, Journal of Energy Resources. ASME 123, 260-269.

10 Nguyen T.T., Kim S.B., Yoo H.R., Rho Y.W. (2001) Modeling and simulation for pig flow control in natural gas pipeline, J.Mech.Sci.Tech. 15, 8, 1165-1173.

11 Tolmasquim S.T., Nieckele A.O. (2008) Design and control of pig operations through pipelines, Journal of Petroleum Science Engineering 62, 102-110.

12 Esmaeilzadeh F., Mowla D., Asemani M. (2009) Mathematical modeling and simulation of pigging operation in gas and liquid pipelines, Journal of Petroleum Science Engineering 69, 100-106.

13 Saeidbakhsh M., Rafeeyan M., Ziaei-rad S. (2009) Dynamic analysis of small pigs in space pipelines, Oil Gas Sci. Technol. 64, 2, 155-164.

14Lesani M., Rafeeyan M., Sohankar A. (2012) Dynamic analysis of Small Pig through two and three dimensional liquid pipeline, Journal of Applied Fluid Mechanics. 5, 2, 75-83.

15 Sobhani M., Rafeeyan M. (2000) Robust controller design for multivariable nonlinear uncertain systems, Iran. J. Sci. Technol. 24, 3, Transaction B, 345-356.

16 Yaniv O. (1999) Quantitative feedback design of linear and nonlinear control systems, Kluwer Academic Publishers, United States of America.

Final manuscript received in October 2011 Published online in August 2012

\section{Copyright (C) 2012 IFP Energies nouvelles}

Permission to make digital or hard copies of part or all of this work for personal or classroom use is granted without fee provided that copies are not made or distributed for profit or commercial advantage and that copies bear this notice and the full citation on the first page. Copyrights for components of this work owned by others than IFP Energies nouvelles must be honored. Abstracting with credit is permitted. To copy otherwise, to republish, to post on servers, or to redistribute to lists, requires prior specific permission and/or a fee: Request permission from Information Mission, IFP Energies nouvelles, fax.+33147527096, or revueogst@ifpen.fr. 